Int. J. Dev. Biol. 57: 85-93 (2013)

doi: $10.1387 / \mathrm{ijdb} .120033 \mathrm{gb}$

\title{
Characterization and expression analysis of mcoln 1.1 and mcoln 1.2, the putative zebrafish co-orthologs of the gene responsible for human mucolipidosis type IV
}

\author{
ANNA BENINI ${ }^{1}$, ANDREA BOZZATO ${ }^{1}$, SILVIA MANTOVANELLI' ${ }^{1}$ LAURA CALVARINI ${ }^{1}$, EDOARDO GIACOPUZZI ${ }^{1}$, \\ ROBERTO BRESCIANI ${ }^{1}$, SILVIA MOLERI ${ }^{2}$, DANIELA ZIZIOLI ${ }^{1}$, MONICA BELTRAME² and GIUSEPPE BORSANI*,1
}

\author{
${ }^{1}$ Dipartimento di Scienze Biomediche e Biotecnologie, Universita' degli Studi di Brescia, Italy and \\ ${ }^{2}$ Dipartimento di BioScienze, Universita' degli Studi di Milano, Milano, Italy
}

\begin{abstract}
Mucolipidosis type IV (MLIV) is an autosomal recessive lysosomal storage disorder caused by mutations in the MCOLN1 gene coding for mucolipin-1 (TRPML1). TRPML1 belongs to a transient receptor potential channels (TRP) subfamily, which in mammals includes two other members: mucolipin-2 (TRPML2) and mucolipin-3 (TRPML3). Bioinformatic analysis of the Danio rerio (zebrafish) genome and trascriptome revealed the presence of five different genes related to human mucolipins: mcoln1.1, mcoln 1.2, mcoln2, mcoln3.1 and mcoln3.2. We focused our efforts on the characterization of the two putative zebrafish MCOLN1 co-orthologs. Transient-expression experiments in human HeLa cells demonstrated that fish Mcoln1.1 and Mcoln 1.2, similarly to TRPML1, localize to late endosomal/lysosomal compartments. Real-Time PCR (RT-PCR) experiments showed that both genes are maternally expressed and transcribed at different levels during embryogenesis. RT-PCR analysis in different zebrafish tissues displayed ubiquitary expression for mcoln 1.1 and a more tissue-specific pattern for $m c o l n 1.2$. Spatial and temporal expression studies using whole-mount in situ hybridization confirmed that both genes are maternally expressed and ubiquitously transcribed during gastrulation and early somitogenesis. Notably, in the next developmental stages they are more expressed in neural regions and in retina layers, tissues affected in MLIV. Interestingly, mcoln 1.1 is detected, from 10 somite-stage until to $36 \mathrm{hpf}$, in the yolk syncytial layer (YSL) and in the intermediate cell mass (ICM), the earliest site of hematopoiesis. Overall, the redundancy of mucolipins together with their expression profile support the biological relevance of this class of proteins in zebrafish. The data herein presented indicate that Danio rerio could be a suitable vertebrate model for the study of some aspects of MLIV pathogenesis.
\end{abstract}

KEY WORDS: mucolipidosis type IV, mucolipin, zebrafish, TRPML1, mcoln1

Mucolipidosis type IV (MLIV; OMIM 252650) is an autosomal recessive lysosomal storage disorder characterized by severe psychomotor delay, evident by the end of the first year of life, and slowly progressive visual impairment during the first decade as a result of a combination of corneal clouding and retinal degeneration (Frei et al., 1998; Merin et al., 1975). The majority of the cases $(80 \%)$ are reported in individuals of Ashkenazi Jewish (AJ) descent (Bargal et al., 2000). MLIV is caused by mutations in the cation channel TRPML1 (also named mucolipin1), encoded by MCOLN1, a gene localized at chromosome 19p13.2-13.3, and apparently ubiquitously expressed (Bargal et al., 2000; Bassi et al., 2000;
Sun et al., 2000). MCOLN1 is part of a gene family together with MCOLN2 and MCOLN3 both mapping at chromosome 1p22.3, encoding TRPML2 and TRPML3 proteins, respectively (Cheng et al., 2010). While there are no reports associating MCOLN2 impairment with diseases, mutations in the mouse Mcoln3 gene result in the varitint-waddler phenotype characterized by diluted coat color and auditory and vestibular problems. TRPML1 is a protein characterized by six transmembrane-spanning domains with both

Abbreviations used in this paper: ICM, intermediate cell mass; TRP, transient receptor potential channel; TRPML, TRP-mucolipidosis; YSL, yolk syncytial layer.

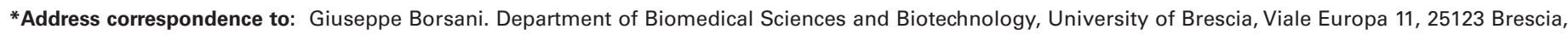
Italy. Tel: +39-030-371-7241. Fax: +39-030-370-1157. e-mail: gborsani@med.unibs.it
}

Supplementary Material (four tables) for this paper is available at: http://dx.doi.org/10.1387/ijdb.120033gb 
$\mathrm{N}$ - and $\mathrm{C}$-terminal tails oriented toward the cytosol and the pore region located between transmembrane segments five and six. It shows topological homology to other members of the TRP (Trans Receptor Potential) super-family of ion channels. Electrophysiological studies indicate that TRPML1 is an inwardly (from lumen to cytoplasm) rectifying channel permeable to $\mathrm{Ca}^{2+}, \mathrm{Na}^{+}, \mathrm{K}^{+}$and $\mathrm{Fe}^{2+}$ or $\mathrm{Mn}^{2+}$, and whose activity is modulated by $\mathrm{pH}^{2}$ and $\mathrm{Ca}^{2+}$ (Cheng et al., 2010; Kiselyov and Patterson, 2009; Puertollano and Kiselyov, 2009). However, the selectivity and the mechanisms of TRPML1 activation under physiological conditions remain still unclear.

MCOLN1 is localized at late endosomes and lysosomes compartments. Two acidic di-leucine consensus motifs positioned at the $\mathrm{N}$ - and $\mathrm{C}$-terminal tails regulate TRPML1 trafficking to the late endosomal pathway (Miedel et al., 2006; Pryor et al., 2006; Vergarajauregui and Puertollano, 2006). Overexpressed wild type TRPML1 colocalizes to late endocytic structures and induces an aberrant distribution of these compartments (Manzoni et al., 2004). TRPML1 is apparently required for efficient fusion of both late endosomes and autophagosomes with lysosomes. The absence of a functional TRPML1 protein results in impaired autophagosome degradation and in their accumulation in MLIV fibroblasts (Vergarajauregui et al., 2008). Autophagic stress may cause accumulation of damaged organelles, as mitochondria, making the cells more susceptible to pro-apoptotic signals. According to this model, Jennings et al., showed that MLIV fibroblasts accumulate fragmented mitochondria and exhibit increased sensitivity to apoptosis induced by $\mathrm{Ca}^{2+}$ mobilizing agonists (Jennings et al., 2006). A recent study demonstrated that TRPML1 functions as a $\mathrm{Fe}^{2+}$ permeable channel in late endosomes and lysosomes (Dong et al., 2008).

The generation of two different MLIV animal models, Drosophila melanogaster and Mus musculus, confirmed that absence of a

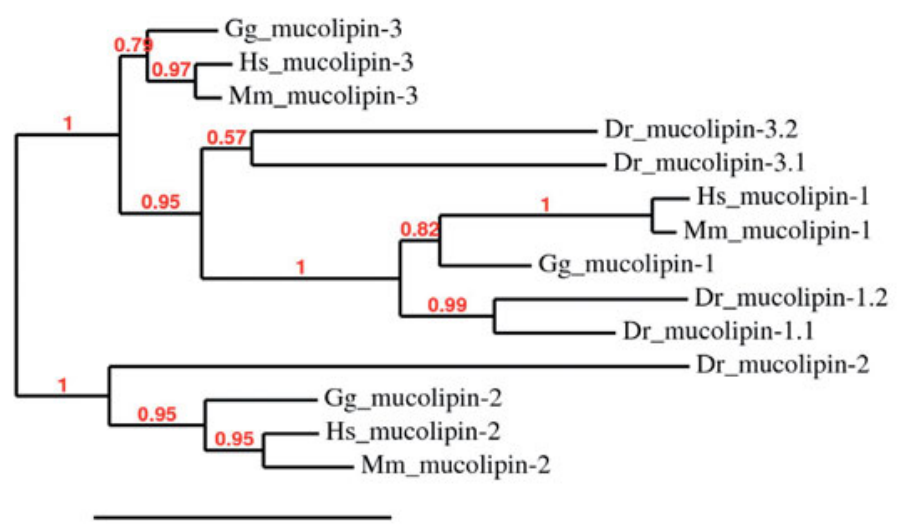

0.3

Fig. 1. Unrooted tree showing phylogenetic analysis results for human (Hs), mouse (Mm), chicken ( $\mathrm{Gg}$ ) and zebrafish (Dr) mucolipin polypeptides. The horizontal bar represents a distance of 0.3 substitutions per site. functional TRPML1 polypeptide results in phenotypes with several analogies with MLIV such as dense inclusion bodies in all cell types, severe retinal degeneration, elevated plasma gastrin, and vacuolization in parietal cells (Venugopal et al., 2007), autophagy defection (Micsenyi et al., 2009; Venkatachalam et al., 2008). Studies on CUP-5, the Caenorhabditis elegans ortholog of MCOLN1, have shown that this protein is involved in endocytic processes and lysosome biogenesis and function (Fares and Greenwald, 2001; Schaheen et al., 2006). Interestingly, the endocytosis defect observed in cup -5 mutants could be rescued by the transgenic expression of human MCOLN1 or MCOLN3 (Treusch et al., 2004).

A recent study identified LAPTM4a and LAPTM5, two members of the lysosome associated protein transmembrane (LAPTM) family, as novel interaction partners of TRPML1 (Vergarajauregui et al., 2011). Overexpression of LAPTM4b caused enlargement of lysosomes and defective lysosomal degradation, indicating that LAPTMs are important for proper lysosomal function. Lysosomal swelling induced by LAPTM4b was rescued by expression of TRPML1, suggesting a functional connection between the two proteins. Interestingly, we previously demonstrated that LAPTM4a and LAPTM5 are 3- and 7-fold up-regulated, respectively, in fibroblasts of MLIV individuals (Bozzato et al., 2008).

Interestingly, a study from Medina and coworkers (Medina et al., 2011) suggests that MCOLN1 may represent a therapeutic tool for disorders associated with intracellular storage. The transcription factor EB (TFEB) regulates lysosomal exocytosis both by inducing the release of intracellular $\mathrm{Ca} 2+$ through its target gene MCOLN1 and by increasing the population of lysosomes ready to fuse with the plasma membrane. The induction of lysosomal exocytosis by TFEB promotes cellular clearance in lysosomal storage diseases in which the lysosomal degradative capacity of cells is compromised.

To gain further insights into the biological role of the MCOLN1 we decided to utilize Danio rerio (zebrafish), an animal model that offers a powerful combination of low cost, rapid in vivo analysis and complex vertebrate biology. In the present study we have identified five different fish genes related to human mucolipins. Being our interest focused on the pathogenesis of MLIV, we concentrated our efforts on the characterization of mcoln1.1 and mcoln1.2, the putative co-orthologs of human MCOLN1 gene.

\section{Results}

\section{Identification of mucolipin genes in zebrafish}

Human MCOLN1, MCOLN2, and MCOLN3 polypeptide sequences were used as query to isolate genes encoding for mucolipins in zebrafish, using both the TBLASTN and BLAT algorithms vs. the Zv8 assembly (Dec. 2008) of zebrafish genomic sequences. This analysis, subsequently refined using the latest Zv9 assembly (Jul. 2010), led to the identification of five putative mucolipin genes.

All genes appear to be transcribed, as demonstrated by the

TABLE 1

\section{GENERAL FEATURES OF MUCOLIPIN GENES IN ZEBRAFISH}

\begin{tabular}{|c|c|c|c|c|}
\hline Gene name & Location in Zv9 genome assembly & Ensembl Gene ID & Number of exons & Protein length \\
\hline mcoln1.1 & Chr $1: 46,142,380-46,171,267$ forward strand & ENSDARG00000002285 & 15 & 581 \\
\hline mcoln1.2 & Chr 3:6,681,201-6,724,884 reverse strand & ENSDARG00000058848 & 13 & 565 \\
\hline mcoln2 & Zv9 scaffold3544: 6,525-22,546 reverse strand & ENSDARG00000018722 & 18 & 561 \\
\hline mcoln3.1 & Chr 23:44,968,865-44,980,038 reverse strand & ENSDARG00000043034 & 14 & 513 \\
\hline mcoln3.2 & Chr 2:1,760,876-1,787,181 forward strand & ENSDARG00000078363 & 12 & 541 \\
\hline
\end{tabular}



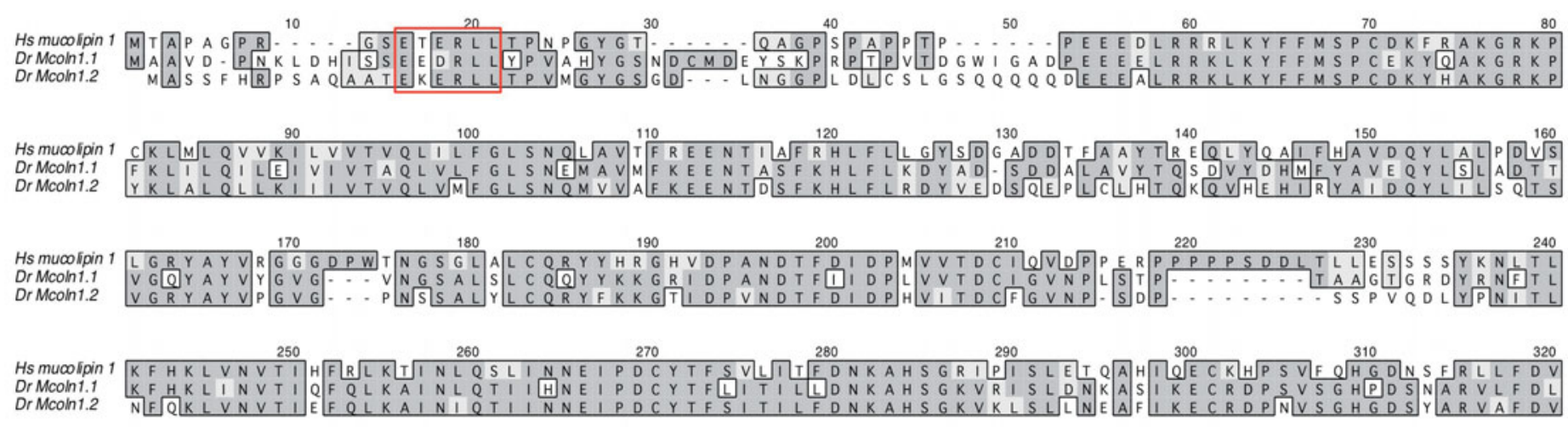

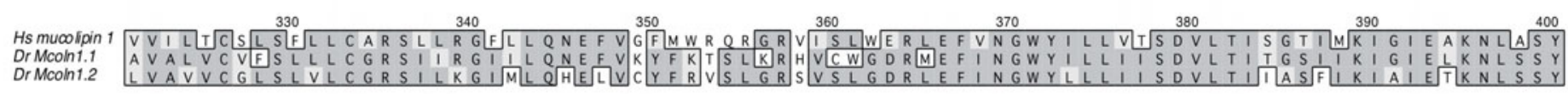

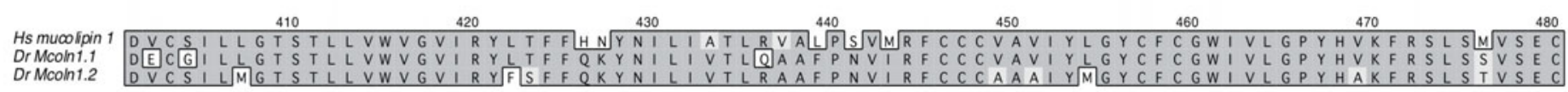

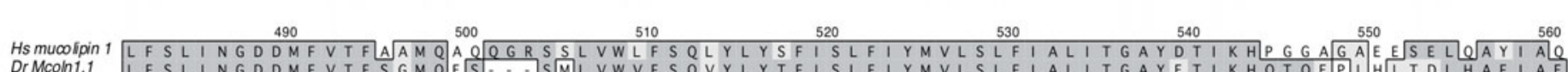

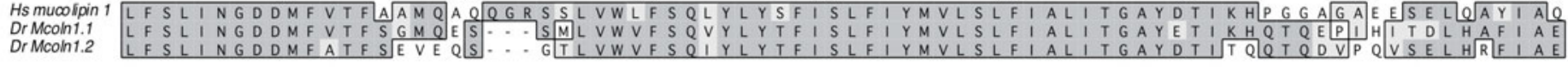
DrMcoint.2 LFSLINGDDMFATFSEVEQS. . GTLVWVFSQIYLYTFISLFIYMVLSLFIALITGAYDTITQQTQDVPQVSELHREIAE

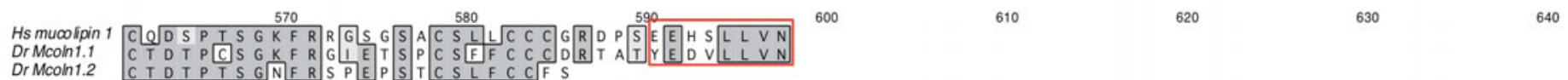

Fig. 2. Multiple sequences alignment of human (Hs) mucolipin-1 (Ensemble Protein ID: ENSP00000264079), zebrafish (Dr) Mcoln1.1 (Ensemble Protein ID: ENSDARP00000118341) and zebrafish (Dr) Mcoln1.2 (Ensemble Protein ID: ENSDARP00000076235) polypeptides by ClustalW2 software. Residues that are identical are shown on a dark grey background; those on a light grey background are the conservative substitutions. The red rectangle marks the two di-leucine lysosomal targeting consensus motifs. Notably this motif is not present at C-terminal of the Dr Mcoln 1.2 protein.

presence of EST sequences in dbEST (data not shown), and their general features are summarized in Table 1. A phylogenetic analysis performed on vertebrate mucolipins indicates that there are two putative orthologs of MCOLN1 and MCOLN3while a single MCOLN2 gene is present in the teleost (Fig. 1). We named the newly-discovered genes mcoln1.1, mcoln1.2, mcoln2, mcoln3.1 and mcoln3.2 according to the Zebrafish Nomenclature Committee (ZNC) guidelines.

We decided to focus our studies on mcoln1.1 and mcoln1.2, the two putative orthologs of MCOLN1 disease gene. mcoln1.1 is composed by 15 exons and is located on chromosome 1. We experimentally derived the sequence of the transcript through the analysis of a number of IMAGE cDNA clones, including one from the Zebrafish Gene Collection (ZGC:63619, IMAGE:5602690) that does not indeed contain the entire ORF. The predicted protein shows a high degree of amino acid sequence identity (62\%) to human MCOLN1. mcoln 1.2 is composed by 13 exons and is located on chromosome 3. Since we could not identify cDNA clones containing the entire coding sequence of the gene, the ORF has been obtained by RT-PCR amplification and DNA sequencing of overlapping portions of the gene transcript. The encoded protein shows a high level of identity (57\%) to MCOLN1. A multiple sequence alignment among Hs MCOLN1, DrMcoln1.1 and DrMcoln1.2 polypeptides is shown in Fig. 2. Besides the high level of identity among the 3 sequences, it is possible to notice that Mcoln1.2 lacks a portion of the sequence at $\mathrm{COOH}$ terminus, that is encoded by the last exon in the other two genes. Interestingly, this exon encodes a sequence corresponding to the C-terminus lysosomal targeting di-leucine motif highlighted in Fig. 2. The exon-intron gene organization of mcoln1.1 and mcoln1.2 is similar to the human counterpart and also the intron positions (with one exception) are conserved in the two species (Fig. 3).

The analysis of the chromosomal regions harboring the human and the Danio rerio mucolipin genes, carried out using the Genomicus synteny browser, allowed to identify conserved syn-

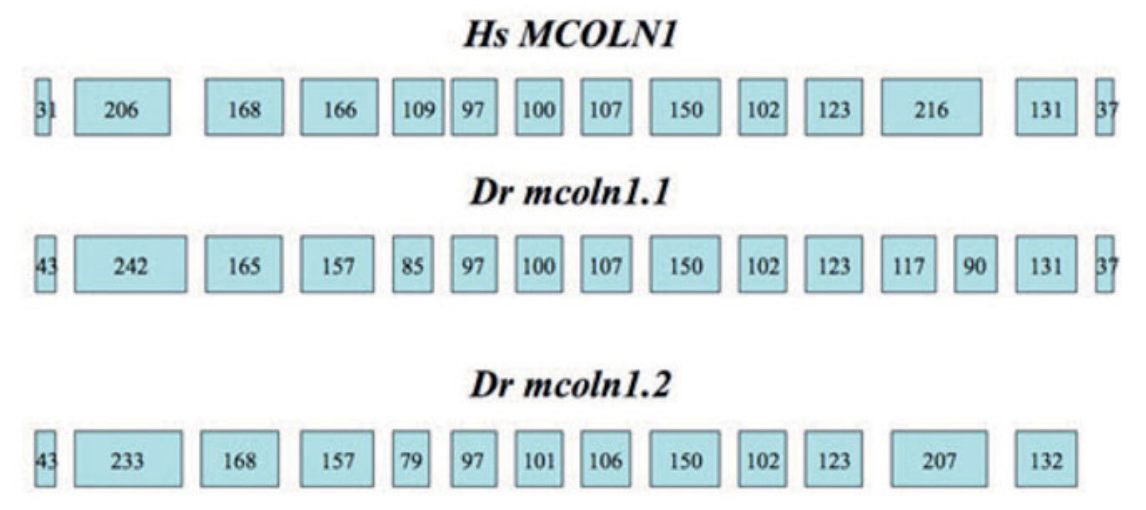

Fig. 3. Exon structure of human (Hs) MCOLN1 and zebrafish (Dr) mcoln 1.1 and Dr mcoln 1.2 genes. Numbers within boxes indicate the nucleotide length of the exons. 
Zebrafish Chr. 1

$\operatorname{map} 2 k 7$

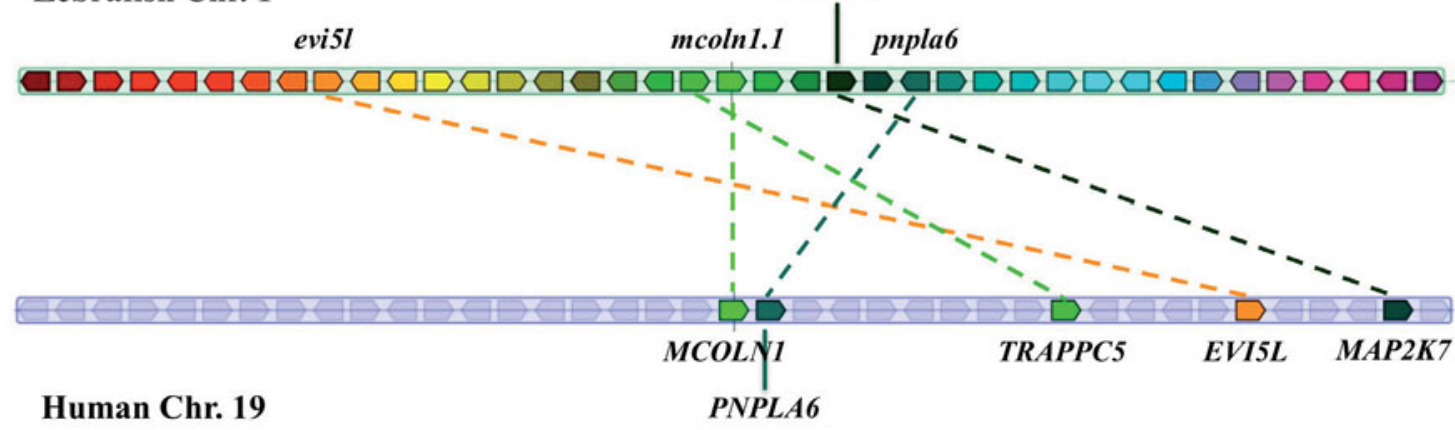

Fig. 4. Graphical representation of conserved synteny around the MCOLN1 locus between Danio rerio chromosome 1 and Homo sapiens chromosome 19 generated using the Genomicus synteny browser. Dashed lines connect orthologous gene pairs within the two clusters. This analysis was performed based on the latest genome assemblies available (Danio rerio Zv9 and Homo sapiens Genome Reference Consortium build 37).
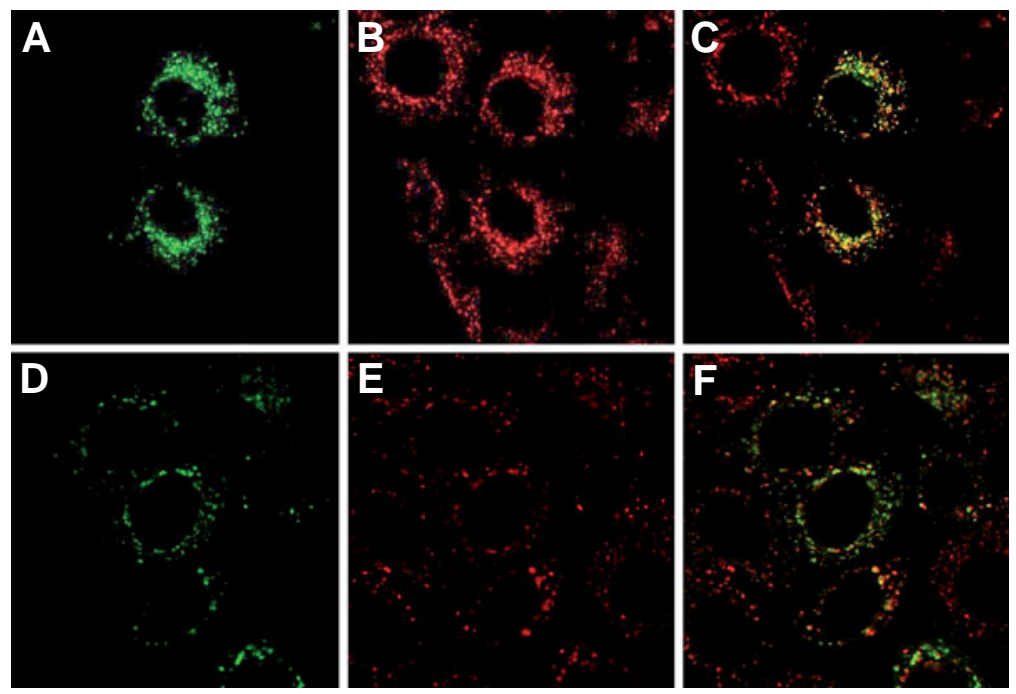

Fig. 5 (Above). Subcellular localization of zebrafish Mcoln1.1 (A) and Mcoln1.2 (D) proteins transiently expressed in HeLa cells. LAMP1 positive vesicles are shown in (B) and (E). A partial co-localization of both zebrafish proteins was observed in LAMP1-positive vesicles (C) and (F).
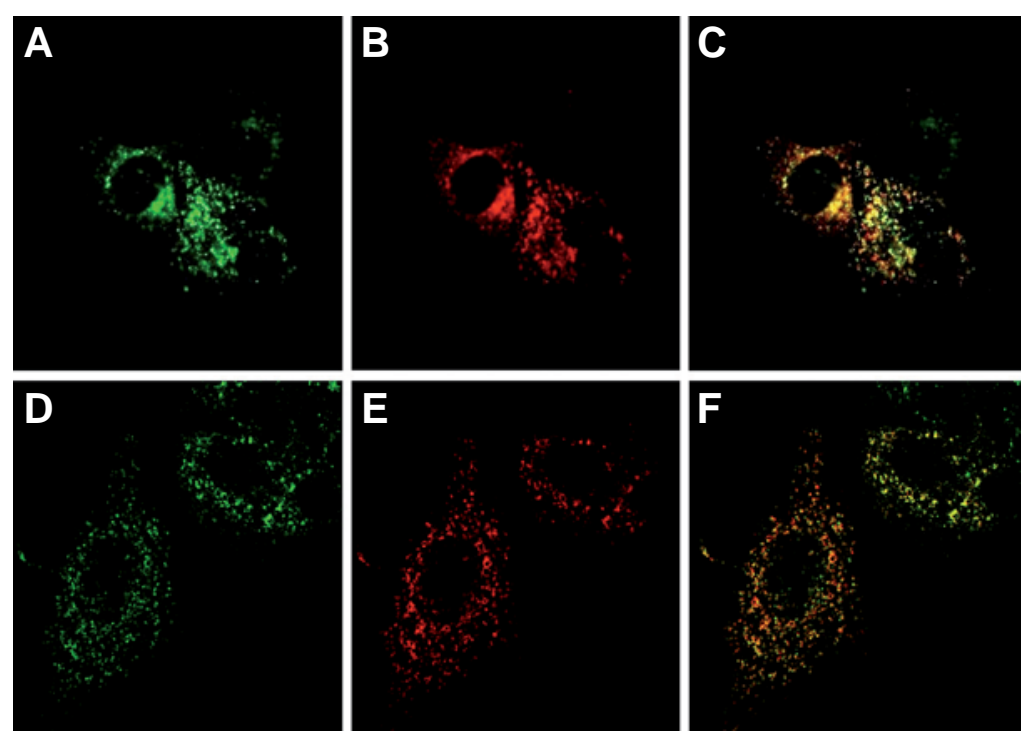

Fig. 6. Subcellular localization of zebrafish Mcoln1.1 (A) and Mcoln1.2 (D) polypeptides as well as human TRPML1 $(B, E)$ in transiently transfected HeLa cells. Co-localizations between the human and the zebrafish polypeptides are shown in (C) and (F). teny only between MCOLN1 and mcoln1.1 (Fig. 4). Similar results have been obtained using the Synteny Database (data not shown).

\section{Subcellular localization of Mcoln1.1 and Mcoln1.2}

Previous works report that human mucolipin partially colocalizes with the late endosomes/lysosomes marker LAMP1 (lysosome-associated membrane protein 1) (Manzoni et al., 2004). To verify if zebrafish Mcoln 1.1 and Mcoln 1.2 proteins show a similar subcellular distribution their coding sequences were cloned separately in the pEGFPC2 vector, generating two mucolipin-EGFP fluorescent fusion proteins. Subsequently pEGFPC2-mcoln1.1 and pEGFPC2-mcoln1.2 were individually transiently expressed in the human HeLa cell line. These experiments indicate a partial co-localization, for both zebrafish proteins, in LAMP1-positive vesicles (Fig. 5). To compare the subcellular distribution of both zebrafish mucolipin-1 proteins to that of human TRPML1, we performed a co-transfection in HeLa cells with PCMV-Tag5A-MCOLN1 and pEGFPC2-mcoln1.1 or pEGFPC2-mcoln1.2. Ahigh level of co-localization was evident in both experiments indicating that human TRPML1 and its zebrafish putative co-orthologs behave in a similar manner when overexpressed in a cellular system (Fig. 6). Then we cloned the mcoln1.1 ORF in a Cterminal c-myc tagging vector, $\mathrm{pCMV}$-Tag5 $\mathrm{A}$, to evaluate the subcellular distribution of both Mcoln1 zebrafish proteins at the same time. mcoln 1.1 and mcoln1.2proteins co-localized just partially but appear to be closely contiguous (Fig. 7).

\section{mcoln1.1 and mcoln1.2 expression during development} and in adult organs

To analyze mcoln 1.1 and mcoln1.2 temporal expression patterns we performed Real-Time PCR assays on CDNA obtained from different zebrafish developmental stages. Expression levels are reported in Fig. 8 relatively to the 1 -cell stage and normalized to elongation factor $1 \alpha(e f 1 \alpha)$ gene. Both genes have a maternal and zygotic expression. mcoln 1.1 expression decreases rapidly in the first day post fertilization and remains stable until the adult age. mcoln 1.2 is expressed in the first hours of development, but low levels of this mRNA are detected during the epiboly and somitogenesis stages, progressively increasing again in the hatching period and in mature age. We also performed RT-PCR experiments to evaluate mcoln1.1 and mcoln 1.2 expression in organs dissected from adult zebrafish. While 

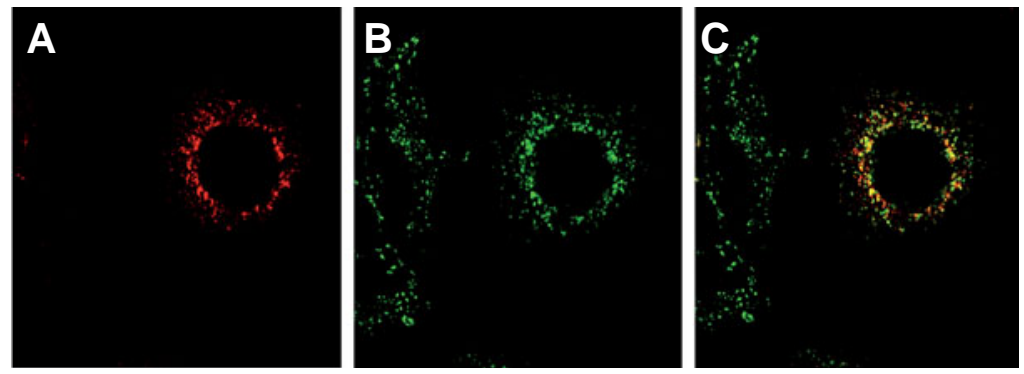

At $48 \mathrm{hpf}$ the mcoln1.1 expression signal shifts into the cephalic region of the central nervous system and is also present in the primordial of the pectoral bud (Fig. 10H). This expression pattern remains almost unchanged in the following developmental stages. A peculiar mcoln1.1 expression is present in the yolk (Fig. 10P) between the second and the third day of development. We have detected a similar spotted expression pattern using an ISH probe for dct (dopachrome tautomerase, data not shown), an early marker for melanoblasts (Kelsh et al., 2000), suggesting that mcoln1.1 is expressed in pigmented cells of the yolk. mcoln1.2 is also a maternally transcribed gene (Fig. 11 reveals a partial co-localization of the two polypeptides (C).

the mcoln1.1 gene seems to be ubiquitously expressed, mcoln 1.2 appears to be differentially expressed in the tissues analyzed (Fig. 9).

\section{Whole-mount in situ hybridization}

To study the spatial and tissue-specific patterns of mcoln 1.1 and mcoln1.2 expression, we performed whole-mount in situ hybridization on zebrafish embryos with specific ribonucleotide anti-sense probes. To assess the specificity of hybridizations, sense probes were also used in parallel control experiments at all stages and no staining was detected in any embryo (data not shown). This analysis confirmed that mcoln1.1 is maternally expressed, being already expressed in zygotes (Fig. $10 \mathrm{~A}$ ) and in the first hours of development (Fig. 10 B,C). The gene is ubiquitously expressed during gastrulation. At the end of epiboly (Fig. 10D) and in the next somitogenesis (Fig. 10E) a higher mcoln1.1 expression can be detected in the rostral region where the primordial of neural tissues originate (Appel, 2000) and in the posterior yolk syncytial layer (YSL, Fig. 10F). At $24 \mathrm{hpf}$ mcoln1.1 is detected in the central nervous system (ventricular zone, tectum, midbrain) (Fig. 10K), in the eye (Fig. 10L), in the otic vescicle (Fig. 10L), in the intermediate cell mass (ICM) of mesoderm and in YSL (probe staining is particularly strong in the terminal region of the yolk extension) (Fig. 10M). At $36 \mathrm{hpf}$ staining is still present in ICM (Fig. 10N).

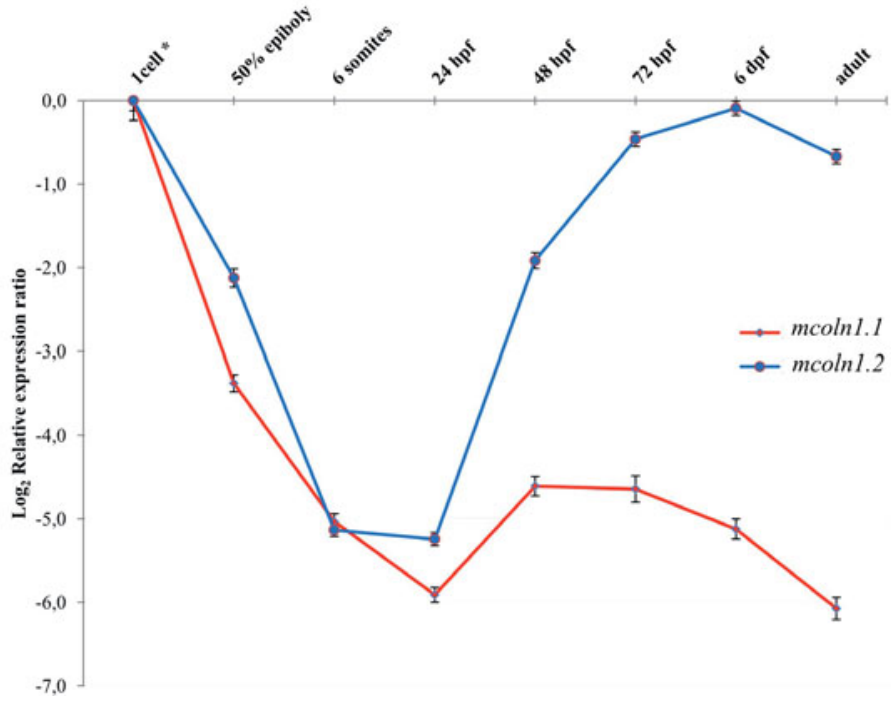

Fig. 8. Real Time PCR expression analysis of mcoln 1.1 and mcoln 1.2 genes throughout Danio rerio development. All reactions were run in triplicate. The relative expression levels, represented as the mean $\pm S E M$ in $\log _{2}$ scale, were determined with respect to the 1-cell stage and normalized to elongation factor $1 \alpha(\mathrm{ef} 1 \alpha)$.

A-C) and shows a ubiquitous expression until $90 \%$ epiboly (Fig. 11D). During somitogenesis (6-15 somites) mcoln1.2 expression can be also detected in the rostral region, while only a faint signal is present in the caudal region (Figure $11 \mathrm{E}-\mathrm{F})$. At $24 \mathrm{hpf}$, its expression is localized in the central nervous system (telencephalon, rhombencephalon and cerebellum Fig. $11 \mathrm{~K}, \mathrm{~L}$ ), in the otic vesicles (Fig. 11K) and in the eye region (Fig. 11L). At $36 \mathrm{hpf}$, the probe signal is still predominant in the brain region, particularly marked in the rhombencephalon, cerebellum, diencephalon and telencephalon
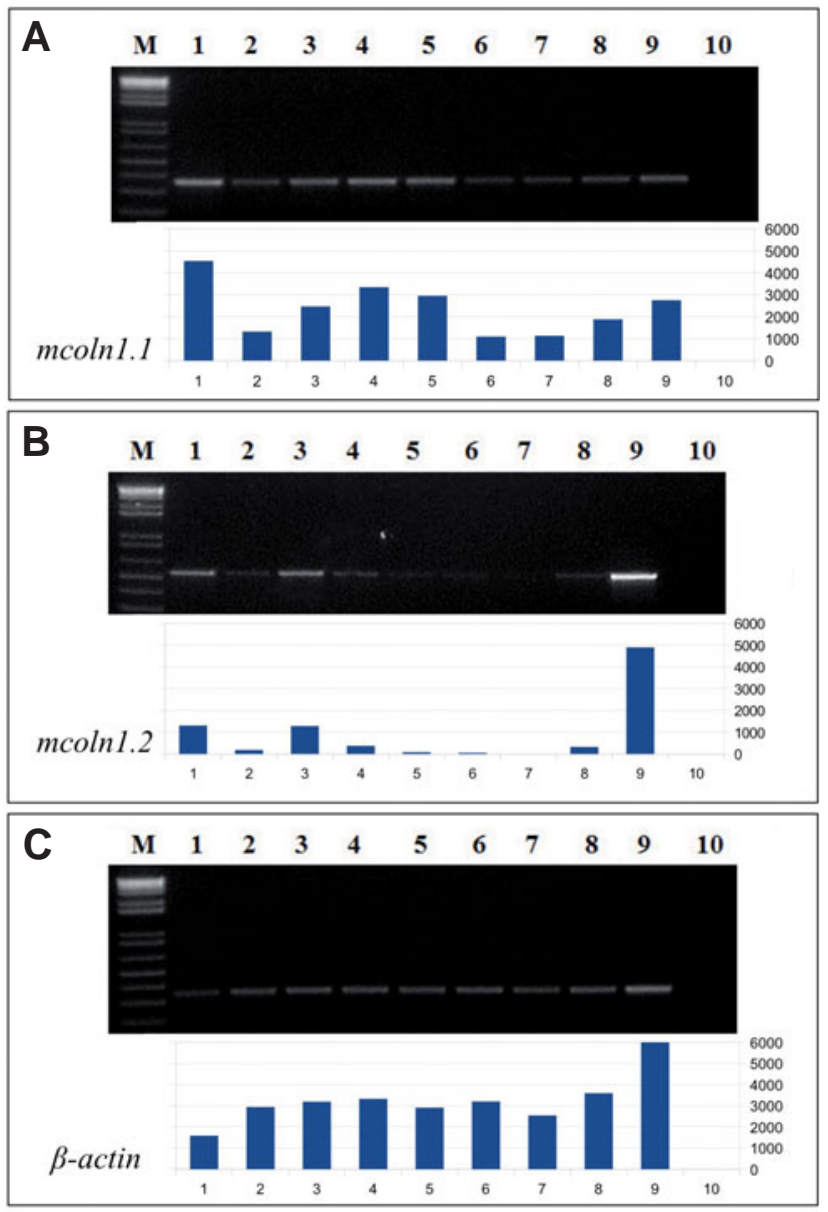

Fig. 9. RT-PCR expression analysis of mcoln 1.1 and mcoln 1.2 in adult zebrafish tissues. Beta-actin was also amplified as housekeeping gene internal control. 1: brain; 2: intestine; 3: eye; 4: heart; 5: kidney; 6: swim bladder; 7: branchias; 8: testis; 9: ovary; 10: negative control. A densitometric analysis of RT-PCR bands is reported below each panel. The units at the left of the graphs are arbitrary. 

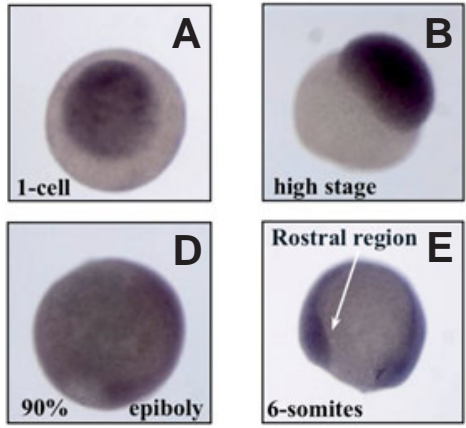

$40 \%$ epiboly

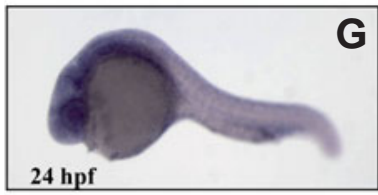

G
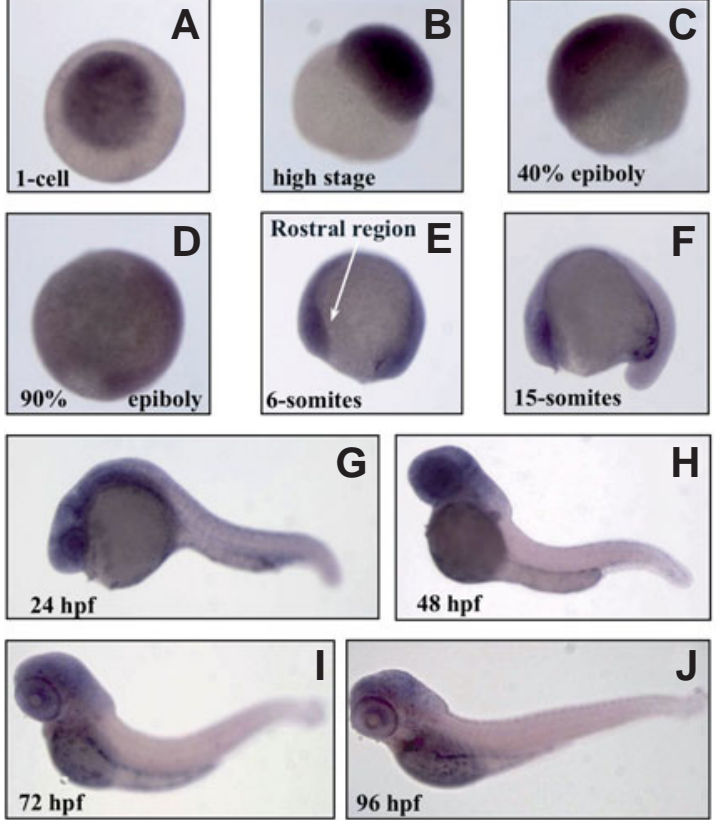

$\mathbf{H}$

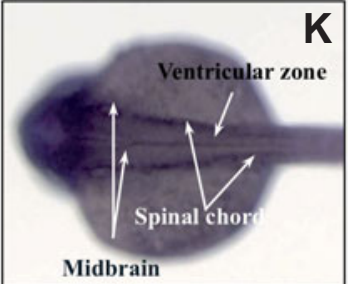

K
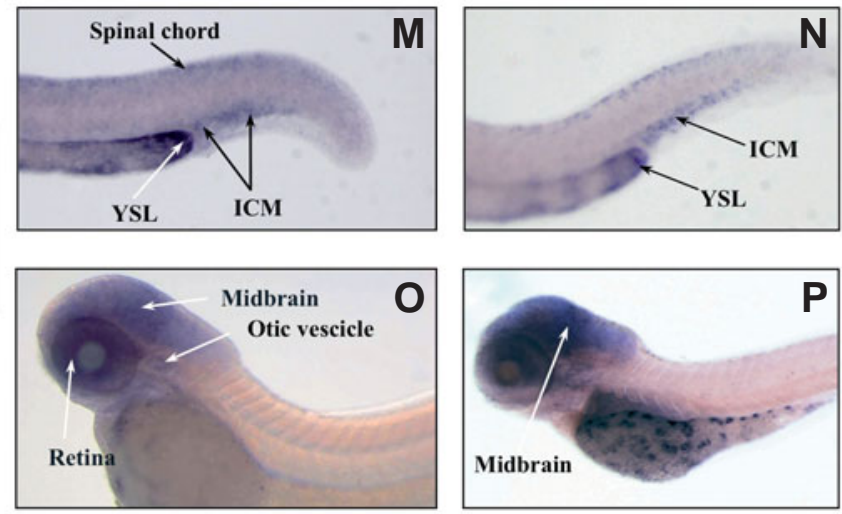

Fig. 10. (A-J) Whole-mount in situ hybridization of mcoln1.1 at different stages of zebrafish development (63X magnification). Dorsal (K) and lateral (L) view of 24 hpf embryo head. Magnification of 24 hpf (M) and 36 hpf (N) embryo tails. Lateral view of 48 hpf (O) and 80 hpf (P) embryo. Images (K-P) were acquired at 115X magnification. Relevant sites of mcoln1.1 gene expression are indicated with arrows.

(Fig.11 O,P). Similarly to mcoln 1.1, at 96 hpf mcoln 1.2 is highly expressed in the eye (Fig. 11R). No spotted expression patters was detected in the yolk using mcoln1.2 probes.

\section{Discussion}

In this study we describe the identification and characterization of the expression profiles of the putative orthologs of the MCOLN1 gene in Danio rerio. In mammals there are three mucolipins encoded by MCOLN1, MCOLN2 and MCOLN3 genes, while in zebrafish the picture is more complex, with the presence of five paralogs. To unravel the phylogenetic origin of the mucolipin gene family in zebrafish, we performed a bioinformatic analysis of the various family members leading to the identification of two putative co-orthologs for the mammalian MCOLN1 gene: mcoln1.1 and mcoln.1.2. The first one shows a higher degree of sequence identity at the protein level with the mammalian gene product. The analysis of the genomic sequences surrounding these genes identify a partial synteny only between Hs MCOLN1 and Dr mcoln1.1, indicating that, from the evolutionary point of view, the latter may be closer to the human counterpart than mcoln 1.2. Similarly, mcoln3.1 and mcoln3.2 represent the co-orthologs of mammalian MCOLN3. Our results indicate that a single ortholog exists for the mammalian MCOLN2 gene, that we named mcoln2.

These findings are not surprising considering that the zebrafish genome was subject to a round of duplication 400 million years ago, after the divergence of fish and mammalian ancestors, resulting in an almost $30 \%$ increase in the total number of genes (Taylor et al., 2003). It is thus not uncommon that for a single gene in mammals more than one ortholog exists in the teleosts. Interestingly, only one MCOLN1-like gene is present in two other teleosts (Takifugu rubripesand Tetraodon nigroviridis), suggesting that the redundancy observed in zebrafish might be the result of an independent gene duplication event. Alternatively, a selective loss has occurred after the partial genome duplication in teleosts leading to the presence of a single mcoln1 gene in some species.

While both human TRPML1 and Dr Mcoln1.1 primary structure show the presence of two di-leucine motifs (D/E)XXXL(L/I) containing sufficient lysosomal targeting information located at the $\mathrm{N}$ - and C-terminus of the protein, the Dr Mcoln1.2 polypeptide lacks the C-terminus signal.

Results from the subcellular localization experiments we performed with Mcoln1.1 and Mcoln1.2 proteins are in agreement with the studies carried out with the human polypeptide. A subset of mucolipin appears to be strictly adjacent to some LAMP1-positive vesicles, but the protein does not exactly co-localize with them. It has been hypothesized that these structures may reasonably represent trafficking intermediates in these fluid cellular compartments (Manzoni et al., 2004).

We observed only a partial co-localization of Mcoln1.1 and Mcoln1.2 when overexpressed in HeLa cells. These results might be due to the different nature of the protein tags and methods of signal detection used in the experiment (direct fluorescence for Mcoln1.2-EGFP-fusion protein and indirect immunofluorescence for Mcoln1.1-Myc fusion polypeptides). In addition, the absence of a C-terminus di-leucine motif in Mcoln1.2 could explain its slightly different localization.

The analysis of expressed sequence tags (EST) present in dbEST indicate that both mcoln1.1 and mcoln1.2 genes are expressed, although at different levels. The evaluation of their expression pattern at different developmental stages by Real-Time PCR has shown a common maternal and zygotic origin for both transcripts, suggesting that they are required in the early stages of zebrafish development. The expression levels of the two genes significantly drop in the first $24 \mathrm{~h}$ of development. While mcoln1.1 expression remains relatively stable afterward, mcoln 1.2 expression increases 

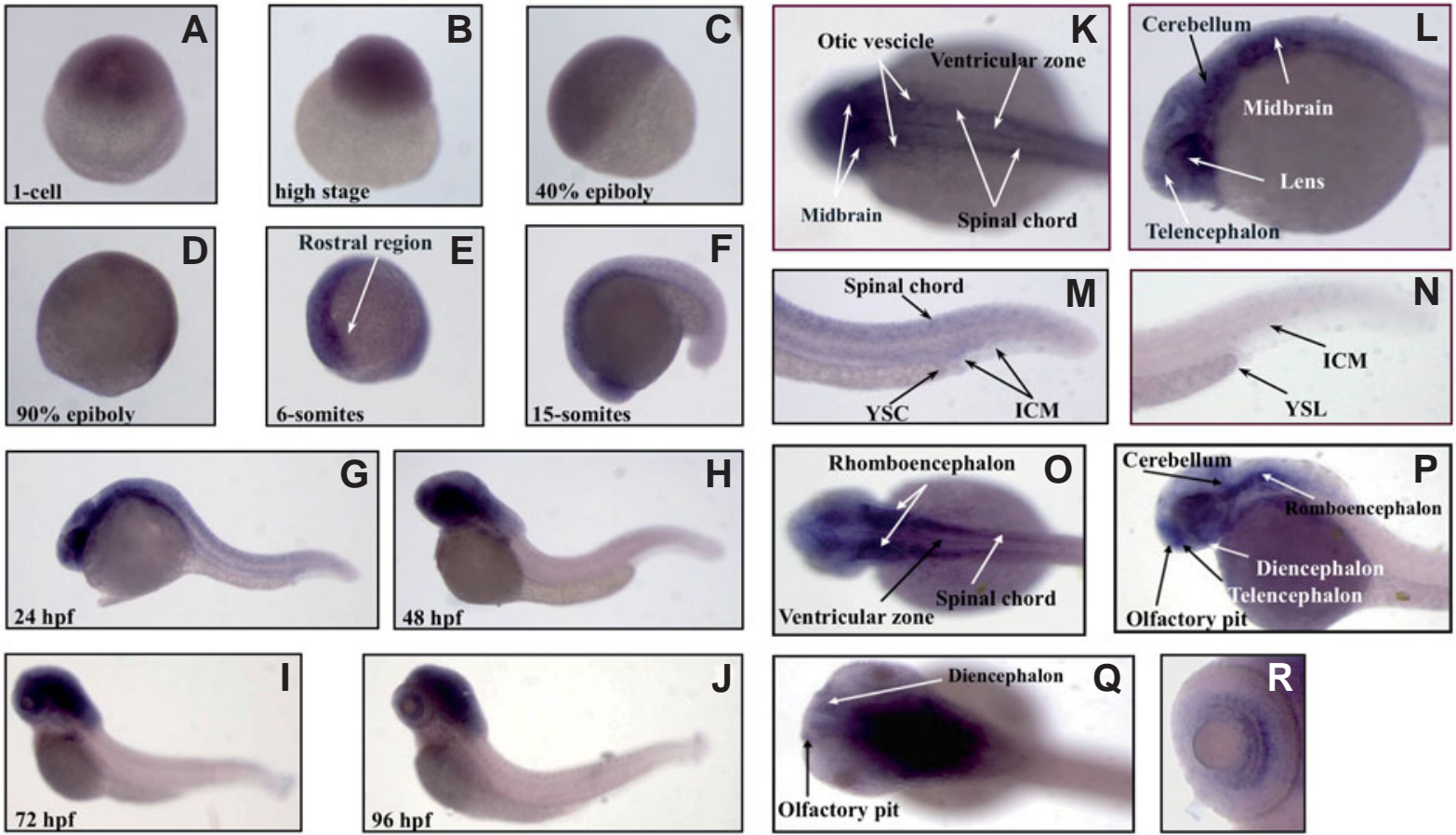

Fig. 11. (A-J) Whole-mount in situ hybridization of mcoln1.2 transcripts during zebrafish development (63X magnification). Dorsa/ (K) and lateral ( $L$, head; $M$, tail) view of 24 hpf embryo. Lateral ( $N$, tail; P, head) and dorsal (0) view of 36 hpf embryo. Dorsal view at 72 hpf (0). High magnification of the eye at $96 \mathrm{hpf}(\mathbf{R})$. Images $(K-R)$ were acquired at $115 X$ magnification. Relevant sites of mcoln1.2 gene expression are indicated with arrows.

in the subsequent developmental stages and in the adult fish.

The expression profiling studies performed by RT-PCR in zebrafish adult tissues suggest that mcoln1.1, similarly to the human counterpart, is ubiquitously expressed, while mcoln1.2 transcript levels appear to be more variable in the samples analyzed.

By whole mount in situ hybridization we analyzed the spatial and temporal expression pattern of mcoln1.1 and mcoln1.2 during development starting from fertilized egg until larval stages (96 hpf). These experiments, consistent with the Real-Time PCR data, confirmed that mcoln 1.1 and mcoln 1.2 are both maternally expressed genes being expressed at the zygote stage. Both genes are ubiquitously expressed during gastrulation and early somitogenesis. It is interesting to note that, in the next developmental stages, mcoln1.1 and mcoln1.2 are more expressed in neural regions and in retina layers, organs particularly involved in MLIV pathogenesis. Peculiar of mcoln1.1, compared to mcoln1.2, is a strong expression detectable since 10 somite-stage until 36 hpf in the yolk syncytial layer (YSL) at the terminal of yolk extension and in the intermediate cell mass region (ICM). In zebrafish, the ICM is the earliest site of hematopoiesis analogous to the blood island in mammals (Bennett et al., 2001). The yolk syncytial layer is the peripheral layer of the yolk cell that lies just below the membrane (Kimmel et al., 1995). The mammalian placenta and the zebrafish YSL provide a homologous function serving as the site of iron transfer between mother and embryo (Donovan et al., 2000). Interestingly, a recent study (Dong et al., 2008) showed that TRPML1, similarly to the divalent metal transporter protein DMT1 (also known as SLC11A2), functions also as $\mathrm{Fe}^{2+}$ permeable channel in late endosomes and lysosomes. The authors suggest that impaired iron transport may contribute to both hematological (such as iron-deficiency anemia) and degenerative symptoms of
MLIV patients. Our study shows that mcoln1.1 is expressed in the developing embryo in tissues actively involved in iron transport/ metabolism, providing a further support for TRPML1 involvement in intracellular $\mathrm{Fe}^{2+}$ transport.

A zebrafish dmt1 null mutant (named chardonnay) has been characterized, showing hypochromic, microcytic anemia (Donovan et al., 2002). The viability of chardonnay mutants suggests the existence of a DMT1-independent pathway for iron to reach the erythroid cells. We speculate that mcoln1.1 can function as $\mathrm{Fe}^{2+}$ channel alternative to $d m t 1$ whereas the different expression pattern suggests that mcoln 1.2 is playing an alternative biological role in the fish.

Our study, together with the data in the literature, indicate that zebrafish can be a suitable model to study the role of mucolipin1 in iron transport and metabolism in vertebrates. Although the expression data of mcoln1.1 and mcoln1.2 indicate that these genes might play a biological role during development and organogenesis, knock-down experiments with antisense morpholinos will be necessary to confirm this hypothesis. Although a mouse model for MLIV has been generated, the characterization has been performed mostly on post-natal and adult animals. The functional inactivation of mcoln1.1 and/or mcoln1.2 genes will allow to evaluate if the phenotypic consequences observed in zebrafish could be exploited to better understand the developmental events leading to MLIV in man.

\section{Materials and Methods}

\section{Bioinformatic analysis}

Nucleotide sequence assembly and editing was performed using both the AutoAssembler version 2.1 (Perkin Elmer-Applied Biosystem) and DNA 
Strider 1.4 (Marck, 1988) software. Zebrafish genomic sequences were analyzed using the University of California Santa Cruz (UCSC) Genome Browser (http://genome.ucsc.edu/) on the Zv8 (Dec. 2008) Danio rerio assembly and subsequently refined on the Zv9 (July 2010) release. We also use the Ensembl zebrafish genome database in our analyses (http:// www.ensembl.org/Danio_rerio/Info/Index). Nucleotide and amino acid sequences were compared to the non-redundant sequences present at the NCBI (National Center for Biotechnology Information) using BLAST and tBLASTN algorithms (Altschul et al., 1990). Multiple sequences alignment was performed using ClustalW algorithm (Higgins, 1994), phylogenetic analysis was made Phylogeny.fr web service and synteny analysis was achieved using both the Genomicus synteny browser (Muffato et al., 2010) and the Synteny Database (Catchen et al., 2009).

\section{Isolation of zebrafish mucolipin cDNAs and generation of expression constructs}

IMAGE (Integrated Molecular Analysis of Gene Expression) Consortium cDNA clones corresponding to mcoln1.1 have been obtained from Geneservice Ltd, UK. The full-insert sequence of clones was determined by automated sequencing using both vector and gene specific oligonucleotide primers. For the generation of the expression constructs, the coding regions of mcoln 1.1 and mcoln 1.2 transcripts were amplified by RT-PCR starting from total RNA extracted from an adult zebrafish (AB strain). The MCOLN1 open reading frame (ORF) was obtained amplifying the cDNA insert of the human IMAGE clone 2517653 using Triple Master PCR System (Eppendorf). Annealing steps were performed at $56^{\circ} \mathrm{C}(M C O L N 1)$ and $62^{\circ} \mathrm{C}$ (mcoln1.1 and mcoln 1.2) for 35 cycles. The PCR products were then digested with appropriate restriction enzymes and cloned in pCMV-Tag5A (MCOLN1 and mcoln1.1) generating MCOLN1 and mcoln1.1 encoding constructs with a C-terminal Myc tag or mcoln1.1 and mcoln1.2 encoding constructs with $\mathrm{N}$-terminal GFP cloned in pEGFPC2 (Supplementary Table S1). Automated sequencing of constructs confirmed the sequences of the cloned inserts.

\section{Immunofluorescence and microscopy}

Human cervical carcinoma cells (HeLa) were used for immunofluorescence studies. HeLa cells were maintained in Dulbecco's modified Eagle's medium (Euroclone Life Sciences), supplemented with $10 \%(\mathrm{v} / \mathrm{v})$ fetal bovine serum (HyClone), $100 \mathrm{U} / \mathrm{ml}$ penicillin, $100 \mu \mathrm{g} / \mathrm{ml}$ streptomycin and $2 \mathrm{mM}$ L-glutamine (Gibco, Invitrogen Life Technologies) at $37^{\circ} \mathrm{C}$ in a $5 \%$ $\mathrm{CO}_{2}$ humidified incubator. The cells were seeded on sterile glass coverslips $(\mathrm{BDH})$ in six wells plates (Corning Life Sciences) and transfections were carried out using FuGENETM 6 (Roche) according to the manufacturer's protocol. Transfected cells were rinsed with PBS, immediately fixed with $3 \%(\mathrm{w} / \mathrm{v})$ PBS-buffered paraformaldehyde for $15 \mathrm{~min}$, washed in PBS, quenched in $50 \mathrm{mM} \mathrm{NH}_{4} \mathrm{Cl}$ for $10 \mathrm{~min}$ and permeabilized in PBS containing $0.5 \%$ of saponin. Subsequently cells were immunolabeled using an indirect procedure in which all incubations (primary, secondary antibodies and washes) were performed in solution containing $0.5 \%$ of saponin. Primary antibodies used were: mouse anti-Myc (Sigma), mouse anti-LAMP1 (lysosome-associated membrane protein 1) (BD Biosciences). Staining was achieved after incubation with Alexa Fluor 555 antibody (Invitrogen). Coverslips were then washed in PBS, mounted on a glass microscopic slide (BDH) with fluorescent mounting medium (Dako) and examined using a Zeiss Axiovert 200 microscope equipped with the confocal laser system LSM 510 META.

\section{Fish breeding and embryo collection}

Wild type zebrafish $A B$ strain was used for all experiments and kept in tanks containing 3-5 liters of fish water at $28^{\circ} \mathrm{C}$ on a $14 \mathrm{~h}$ light/10h dark cycle (Westerfield, 1993). Embryos were collected by natural spawing, staged according to Kimmel et al., (Kimmel et al., 1995) and raised at $28^{\circ} \mathrm{C}$ in fish water $(0.1 \mathrm{~g} / \mathrm{L}$ Instant Ocean Sea Salts, $0.1 \mathrm{~g} / \mathrm{L}$ sodium bicarbonate, $0.19 \mathrm{~g} / \mathrm{L}$ calcium solphate, $0.2 \mathrm{mg} / \mathrm{L}$ methylen blue, $\mathrm{H}_{2} \mathrm{O}$ ) at $28^{\circ} \mathrm{C}$ on a 14 $\mathrm{h}$ light/10 h dark cycle (Westerfield, 1993). Adult zebrafish were bred by natural crosses and fertilized eggs were collected and placed in Petri dishes at $28^{\circ} \mathrm{C}$ in fish water until the desired developmental stage was reached. To examine post-gastrulation stages, regular fish water was replaced by $0.0045 \%$ PTU (1-Phenil-2-thiourea, Sigma) solution. The embryos were dechorionated by hand using sharpened forceps and then fixed in $4 \%$ (wt/vol) paraformaldehyde 1X PBS overnight at $4^{\circ} \mathrm{C}$ (or 2 hours at room temperature), into Petri dishes, dehydrated through sequential washes in $25 \%, 50 \%, 75 \%$ methanol/PBS, $100 \%$ methanol and stored at least overnight at $-20^{\circ} \mathrm{C}$.

\section{RNA extraction, reverse transcription and real time PCR}

Total RNA was extracted from 40 embryos for each different developmental stage analyzed, frozen in liquid nitrogen, using ToTALLY RNATM Kit (Ambion) in conjunction with Phase Lock Gel (Eppendorf) according to manufacturer's protocol. For tissues dissection, the adult fishes were killed by an excess of ethyl 3-aminobenzoate methanesulfonate salt solution (Sigma Aldrich). RNA was quantified using the NanoDrop ND-1000 spectrophotometer (NanoDrop Technologies, Inc.) and checked for quality control with Agilent Bioanalyzer 2100 (Agilent Technologies). $1.5 \mu \mathrm{g}$ of total RNA has been retrotranscribed to cDNA using SuperScript III (Invitrogen) and oligo (dT) primers following the manufacturer's protocol. We have selected exon-spanning primers and TaqMan probes (Supplementary Table S2) using Primer Express 3.0 Software Suite (Applied Biosystems).

For RT-PCR experiments, densitometric analysis of EtBr-stained gel bands was performed using the public domain ImageJ image processing program (http://rsbweb.nih.gov/ij/).

Real-Time PCR was performed using the Applied Biosystem 7500 System (Applied Biosystems). For each quantification, a standard curve was created using appropriate amount of cDNA obtaining amplification efficiencies values close to 2 for all primer combinations. Reactions were performed in a $25 \mu \mathrm{l}$ volume, containing a variable concentration (from 200 to $800 \mathrm{nM}$ ) of specific primers, $200 \mathrm{nM}$ of TaqMan probe, $12.5 \mu \mathrm{l}$ of TaqMan® Gene Expression Master Mix (Applied Biosystems), and $25 \mathrm{ng}$ of reverse transcription reaction solution. The amplification profile used was: denaturation program $\left(95^{\circ} \mathrm{C}\right.$ for $\left.1 \mathrm{~min}\right), 40$ cycles of two steps amplification ( $95^{\circ} \mathrm{C}$ for $15 \mathrm{~s}$ and $60^{\circ} \mathrm{C}$ for $1 \mathrm{~min}$ ). Each reaction was performed in triplicate. To evaluate differences in gene expression we choose a relative quantification method based on the standard curve approach (Pfaffl, 2001). Levels of expression obtained by this method were normalized with that of the endogenous control housekeeping transcript translation elongation factor $1 \alpha(e f 1 \alpha)$. The statistical significance was calculated using one-way ANOVA followed by Dunnett's Multiple Comparison Test. $\mathrm{P}<0.001$ for all data, compared with control (1 cell)

\section{Whole-mount in situ hybridization}

To synthesize the riboprobes against zebrafish mcoln1.1 and mcoln1.2 transcripts, we amplified specific regions by PCR using as templates plasmids containing the cloned cDNAs and oligonucleotide primers carrying at the 5' side the T3 and T7 RNA polymerases promoter consensus sequences (Supplementary Table S3). The amplification conditions were: $95^{\circ} \mathrm{C}$ for 9 min; 4 cycles denaturation at $94^{\circ} \mathrm{C}$ for $30 \mathrm{sec}$, specific annealing temperature for each primer pair for $30 \mathrm{sec}, 72^{\circ} \mathrm{C}$ for $1 \mathrm{~min}$; then 26 cycles at $94^{\circ} \mathrm{C}$ for $30 \mathrm{sec}, 65^{\circ} \mathrm{C}$ for $30 \mathrm{sec}, 72^{\circ} \mathrm{C}$ for $1 \mathrm{~min}$ and $72^{\circ} \mathrm{C}$ for $10 \mathrm{~min}$. Each PCR product was purified using the QIAquick® PCR Purification kit (Qiagen) and quantified with NanoDrop ND-1000. The dct (dopachrome tautomerase) was generated starting from the Zebrafish Gene Collection cDNA clone MGC109860. Antisense and sense RNA probes (Supplementary Table S4) were obtained by in vitro transcription of PCR products with T7 or T3 RNA polymerase (Roche), using a digoxigenin labeling mixture (Roche) according to manufacturer's protocol. Whole-mount in situ hybridizations was performed as previously described (Thisse and Thisse, 2008). Embryos and larvae were collected, dechorionated and incubated at $28^{\circ} \mathrm{C}$ at different stages. Embryos were fixed overnight in 4\% paraformaldehyde (PFA) at $4^{\circ} \mathrm{C}$, dehydrated through an ascending methanol series and stored at $-20^{\circ} \mathrm{C}$. After treatment with proteinase $\mathrm{K}(10 \mu \mathrm{g} / \mathrm{ml}$, Roche $)$, the embryos were hybridized overnight at $65 / 68^{\circ} \mathrm{C}$ with DIG-labeled antisense or sense 
RNA probes (200-400 $\mathrm{ng} / \mathrm{\mu l}$ ). The staining was performed with NBT/BCIP (blue staining solution, Roche) alkaline phosphatase substrates. Embryos were mounted in agarose-coated dishes and images were taken using a Leica MZ16 F stereo microscope.

\section{Acknowledgements}

This work was supported by the Fondazione Cariplo "ZebraGene" Grant to G.B. and by a fellowship from the Consorzio Interuniversitario Biotecnologie (CIB) to A.B. We thank Prof. Marco Presta and the Zebrafish Facility of the University of Brescia for their precious support.

\section{References}

ALTSCHUL, S.F., GISH, W., MILLER, W., MYERS, E.W. and LIPMAN, D.J. (1990). Basic local alignment search tool. $J$ Mol Biol 215: 403-410.

APPEL, B. (2000). Zebrafish neural induction and patterning. Dev Dyn 219: 155-168. BARGAL, R., AVIDAN, N., BEN-ASHER, E., OLENDER, Z., ZEIGLER, M., FRUMKIN, A., RAAS-ROTHSCHILD, A., GLUSMAN, G., LANCET, D. and BACH, G. (2000). Identification of the gene causing mucolipidosis type IV. Nat Genet 26: 118-123.

BASSI, M.T., MANZONI, M., MONTI, E., PIZZO, M.T., BALLABIO, A. and BORSANI, G. (2000). Cloning of the gene encoding a novel integral membrane protein, mucolipidin-and identification of the two major founder mutations causing mucolipidosis type IV. Am J Hum Genet 67: 1110-1120.

BENNETT, C.M., KANKI, J.P., RHODES, J., LIU, T.X., PAW, B.H., KIERAN, M.W., LANGENAU, D.M., DELAHAYE-BROWN, A., ZON, L.I., FLEMING, M.D. et al., (2001). Myelopoiesis in the zebrafish, Danio rerio. Blood 98: 643-651.

BOZZATO, A., BARLATI, S. and BORSANI, G. (2008). Gene expression profiling of mucolipidosis type IV fibroblasts reveals deregulation of genes with relevant functions in lysosome physiology. Biochim Biophys Acta 1782: 250-258.

CATCHEN, J.M., CONERY, J.S. and POSTLETHWAIT, J.H. (2009). Automated identification of conserved synteny after whole-genome duplication. Genome Res 19: 1497-1505.

CHENG, X., SHEN, D., SAMIE, M. and XU, H. (2010). Mucolipins: Intracellular TRPML1-3 channels. FEBS Lett 584: 2013-2021.

DONG, X.P., CHENG, X., MILLS, E., DELLING, M., WANG, F., KURZ, T. and XU, H. (2008). The type IV mucolipidosis-associated protein TRPML1 is an endolysosomal iron release channel. Nature 455: 992-996.

DONOVAN, A., BROWNLIE, A., DORSCHNER, M.O., ZHOU, Y., PRATT, S.J., PAW, B.H., PHILLIPS, R.B., THISSE, C., THISSE, B. and ZON, L.I. (2002). The zebrafish mutant gene chardonnay (cdy) encodes divalent metal transporter 1 (DMT1). Blood 100: 4655-4659.

DONOVAN, A., BROWNLIE, A., ZHOU, Y., SHEPARD, J., PRATT, S.J., MOYNIHAN, J., PAW, B.H., DREJER, A., BARUT, B., ZAPATA, A. et al., (2000). Positional cloning of zebrafish ferroportin1 identifies a conserved vertebrate iron exporter. Nature 403: 776-781.

FARES, H. and GREENWALD, I. (2001). Regulation of endocytosis by CUP-5, the Caenorhabditis elegans mucolipin-1 homolog. Nat Genet 28: 64-68.

FREI, K.P., PATRONAS, N.J., CRUTCHFIELD, K.E., ALTARESCU, G. and SCHIFFMANN, R. (1998). Mucolipidosis type IV: characteristic MRI findings. Neurology 51: $565-569$.

HIGGINS, D.G. (1994). CLUSTAL V: multiple alignment of DNAand protein sequences. Methods Mol Biol 25: 307-318.

JENNINGS, J.J., JR., ZHU, J.H., RBAIBI, Y., LUO, X., CHU, C.T. and KISELYOV, K. (2006). Mitochondrial aberrations in mucolipidosis Type IV. J Biol Chem 281: 39041-39050.

KELSH, R.N., SCHMID, B. and EISEN, J.S. (2000). Genetic analysis of melanophore development in zebrafish embryos. Dev Biol 225: 277-293.

KIMMEL, C.B., BALLARD, W.W., KIMMEL, S.R., ULLMANN, B. and SCHILLING, T.F. (1995). Stages of embryonic development of the zebrafish. Dev Dyn203:253-310.

KISELYOV, K. and PATTERSON, R.L. (2009). The integrative function of TRPC channels. Front Biosci 14: 45-58.
MANZONI, M., MONTI, E., BRESCIANI, R., BOZZATO, A., BARLATI, S., BASSI, M.T. and BORSANI, G. (2004). Overexpression of wild-type and mutant mucolipin proteins in mammalian cells: effects on the late endocytic compartment organization. FEBS Lett 567: 219-224.

MARCK, C. (1988). 'DNA Strider': a 'C' program for the fast analysis of DNA and protein sequences on the Apple Macintosh family of computers. Nucleic Acids Res 16: 1829-1836.

MEDINA, D.L., FRALDI, A., BOUCHE, V., ANNUNZIATA, F., MANSUETO, G., SPAMPANATO, C., PURI, C., PIGNATA, A., MARTINA, J.A., SARDIELLO, M. et al., (2011). Transcriptional activation of lysosomal exocytosis promotes cellular clearance. Dev Cell 21: 421-430.

MERIN, S., LIVNI, N., BERMAN, E.R. and YATZIV, S. (1975). Mucolipidosis IV: ocular, systemic, and ultrastructural findings. Invest Ophthalmol 14: 437-448.

MICSENYI, M.C., DOBRENIS, K., STEPHNEY, G., PICKEL, J., VANIER, M.T., SLAUGENHAUPT, S.A. and WALKLEY, S.U. (2009). Neuropathology of the Mcoln1(-/-) knockout mouse model of mucolipidosis type IV. J Neuropathol Exp Neurol 68: 125-135

MIEDEL, M.T., WEIXEL, K.M., BRUNS, J.R., TRAUB, L.M. and WEISZ, O.A. (2006) Posttranslational cleavage and adaptor protein complex-dependent trafficking of mucolipin-1. J Biol Chem 281: 12751-12759.

MUFFATO, M., LOUIS, A., POISNEL, C.E. and ROEST CROLLIUS, H. (2010) Genomicus: a database and a browser to study gene synteny in modern and ancestral genomes. Bioinformatics 26: 1119-1121.

PFAFFL, M.W. (2001). A new mathematical model for relative quantification in realtime RT-PCR. Nucleic Acids Res 29: e45.

PRYOR, P.R., REIMANN, F., GRIBBLE, F.M. and LUZIO, J.P. (2006). Mucolipin-1 is a lysosomal membrane protein required for intracellular lactosylceramide traffic. Traffic 7: 1388-1398.

PUERTOLLANO, R. and KISELYOV, K. (2009). TRPMLs: in sickness and in health. Am J Physiol Renal Physiol 296: F1245-1254.

SCHAHEEN, L., DANG, H. and FARES, H. (2006). Basis of lethality in C. elegans lacking CUP-5, the Mucolipidosis Type IV orthologue. Dev Biol 293: 382-391.

SUN, M., GOLDIN, E., STAHL, S., FALARDEAU, J.L., KENNEDY, J.C., ACIERNO, J.S., JR., BOVE, C., KANESKI, C.R., NAGLE, J., BROMLEY, M.C. et al., (2000). Mucolipidosis type IV is caused by mutations in a gene encoding a novel transient receptor potential channel. Hum Mol Genet 9: 2471-2478.

TAYLOR, J.S., BRAASCH, I., FRICKEY, T., MEYER, A. and VAN DE PEER, Y (2003). Genome duplication, a trait shared by 22000 species of ray-finned fish. Genome Res 13: 382-390.

THISSE, C. and THISSE, B. (2008). High-resolution in situ hybridization to wholemount zebrafish embryos. Nat Protoc 3: 59-69.

TREUSCH, S., KNUTH, S., SLAUGENHAUPT, S.A., GOLDIN, E., GRANT, B.D. and FARES, H. (2004). Caenorhabditis elegans functional orthologue of human protein h-mucolipin-1 is required for lysosome biogenesis. Proc Natl Acad Sci USA 101: 4483-4488.

VENKATACHALAM, K., LONG, A.A., ELSAESSER, R., NIKOLAEVA, D., BROADIE, K. and MONTELL, C. (2008). Motor deficit in a Drosophila model of mucolipidosis type IV due to defective clearance of apoptotic cells. Cell 135: 838-851.

VENUGOPAL, B., BROWNING, M.F., CURCIO-MORELLI, C., VARRO, A., MICHAUD, N., NANTHAKUMAR, N., WALKLEY, S.U., PICKEL, J. and SLAUGENHAUPT, S.A. (2007). Neurologic, gastric, and opthalmologic pathologies in a murine mode of mucolipidosis type IV. Am J Hum Genet 81: 1070-1083.

VERGARAJAUREGUI, S., CONNELLY, P.S., DANIELS, M.P. and PUERTOLLANO, R. (2008). Autophagic dysfunction in mucolipidosis type IV patients. Hum Mol Genet 17: 2723-2737.

VERGARAJAUREGUI, S., MARTINA, J.A. and PUERTOLLANO, R. (2011). LAPTMs regulate lysosomal function and interact with mucolipin 1: new clues for understanding mucolipidosis type IV. J Cell Sci 124: 459-468.

VERGARAJAUREGUI, S. and PUERTOLLANO, R. (2006). Two di-leucine motifs regulate trafficking of mucolipin-1 to lysosomes. Traffic 7: 337-353.

WESTERFIELD, M. (1993). The zebrafish book, (ed.: Eugene, OR University of Oregon Pr.) 


\section{Further Related Reading, published previously in the Int. J. Dev. Biol.}

Identification and expression analysis of two novel members of the Mesp family in zebrafish Stephen J. Cutty, Rita Fior, Pedro M. Henriques, Leonor Saúde and Fiona C. Wardle Int. J. Dev. Biol. (2012) 56: 285-294

Cloning and developmental expression of zebrafish pdzrn3

Luciana Dente, Gaia Gestri, Michael Tsang, Tetsuhiro Kudoh, Stephen W. Wilson, Igor B. Dawid and Massimiliano Andreazzoli Int. J. Dev. Biol. (2011) 55: 989-993

Characterization and expression pattern analysis of the facilitative glucose transporter 10 gene (slc2a10) in Danio rerio

Nicola Chiarelli, Marco Ritelli, Nicoletta Zoppi, Anna Benini, Giuseppe Borsani, Sergio Barlati and Marina Colombi

Int. J. Dev. Biol. (2011) 55: 229-236

Expression of protocadherin-19 in the nervous system of the embryonic zebrafish Qin Liu, Yun Chen, Fumitaka Kubota, Jean J. Pan and Tohru Murakami Int. J. Dev. Biol. (2010) 54: 905-911

Isolation and expression analysis of foxj1 and foxj1.2 in zebrafish embryos Emil Aamar and Igor B. Dawid

Int. J. Dev. Biol. (2008) 52: 985-991

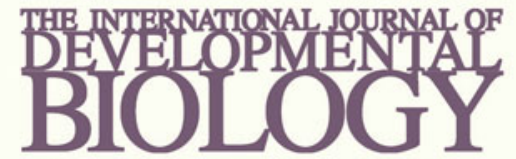

Volume 54 Nos. $6 / 7$ Special Issue
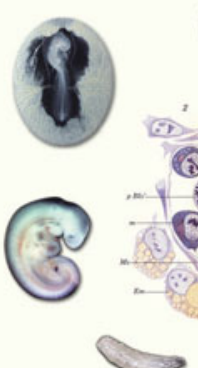

Developmental Hematopoiesis
5 yr ISI Impact Factor $(2011)=2.959$

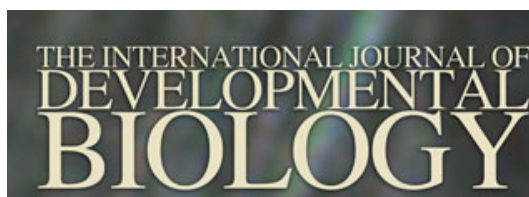

Special Issue
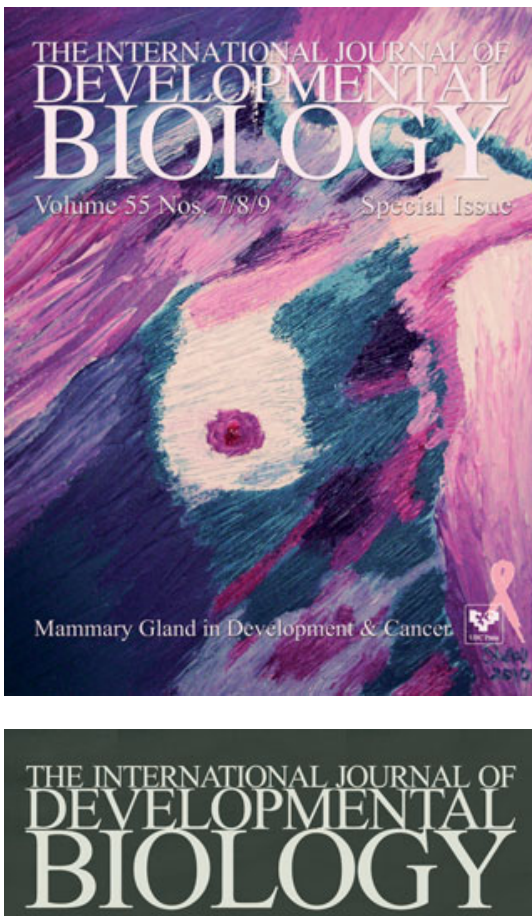

Volume 55 Nos. $4 / 5$

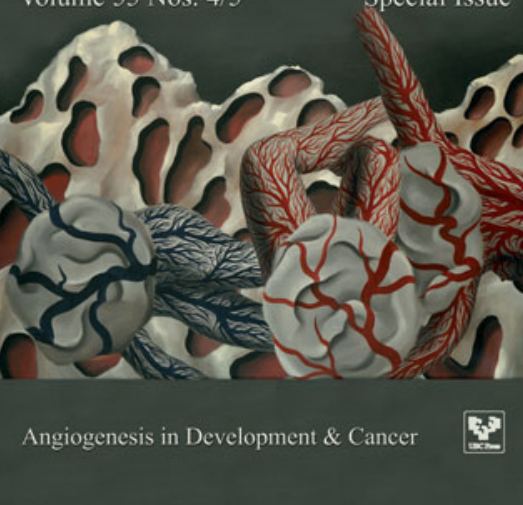

